\title{
Thyroid profile as a marker of poor prognostic factor in patients with acute coronary syndrome: a tertiary care hospital based observational study
}

\author{
Navaraj Paudel, Madhav Alurkar, Ramchandra Kafle, Abhishek Maskey, Subash Sapkota
}

Department of Cardiology, Manipal Teaching Hospital, Pokhara, Nepal.

Corresponding Author: Navaraj Paudel, MCOMS-MTH, Phulbari-11, Pokhara, Kaski, Nepal. Email: drnavarajdm@gmail.com

Abstract

Background and aims: Serum thyroid hormonal changes can occur in acute or chronic non-thyroidal systemic illness including acute coronary syndrome in otherwise euthyroid individuals. In this study we aimed to assess thyroid hormonal profile in patients presenting with acute coronary syndromes (ACS) and compare between ST segment elevated myocardial infarction and unstable angina/Non ST segment elevated myocardial infarction.

Methods: A hospital based, retrospective, observational comparative study was designed. Data of all patients with acute coronary syndrome presenting to hospital were collected from July 2015 through June 2017 in a pre-structured proforma and analyzed.

Results: A total of 200 ACS patients between 23 years to 88 years with mean age of $61.33 \pm 12.30$ years were studied. One hundred and twenty seven $(63.5 \%)$ were males. Among them $116(58 \%)$ was ST segment elevated myocardial infarction (STEMI) patients while $84(42 \%)$ were unstable angina/ non-ST elevated myocardial infarction (UA/ NSTEMI) patients. Total 47 (23.5\%) patients had abnormal TFT of which 28(59.5\%) had Euthyroid Sick Syndrome, 12(25.5\%) had subclinical hypothyroidism, 5(10.6\%) had subclinical hyperthyroidism and 2(4.25\%) had low fT4 with normal fT3 and normal TSH. There was significant difference in TFT in patients with STEMI and UA/NSTEMI $(\mathrm{P}=0.006)$. There were higher rates of heart failure $(\mathrm{p}=0.001 \& 0.003$ in STEMI \& UA/NSTEMI respectively), longer length of hospital stay (3+0.17 days) and high mortality (more than 4 fold) in all types of ACS patients with abnormal TFT than ACS patients with normal TFT.

Conclusion: There is higher prevalence of abnormal thyroid hormonal findings in ACS causing significant morbidity and mortality.

Keywords: Acute coronary syndrome, prognosis, thyroid hormone profile.

\section{DOI: http://dx.doi.org/10.3126/njh.v15i1.19715}

\section{Introduction}

Alteration in the level of serum thyroid hormone profile has been described in several non-thyroidal systemic illnesses including acute heart diseases in otherwise euthyriod patients. This condition has been termed as "Euthyroid Sick Syndrome" and is characterized by decreased serum T3 and /or free T3, increased serum reverse T3 (rT3), plus normal serum TSH, T4, and free T4 levels ${ }^{1}$.Patients belonging to the STEMI group showed early elevations, in addition to higher mean reverse T3(rT3) and lower mean T3 and free T3 levels. ${ }^{1}$ This syndrome has been reported to be found in severe chronic heart failure ${ }^{2}$, in acute myocardial infarction ${ }^{3,4}$ and as a rapidly emerging phenomenon during open-heart surgery. ${ }^{5}$ Additionally hypothyroidism is emerging as a risk for coronary artery disease. ${ }^{6}$

Evaluation of thyroid hormone plasma levels has been done in a number of studies in patients presenting with Acute Coronary Syndrome (ACS) and findings compared between Unstable Angina/Non-ST elevation MI (UA/NSTEMI) and ST Elevation acute MI (STEMI) groups. ${ }^{1,7}$ Some studies have reported association of greater hormonal changes with more severe cardiac events( STEMI and Death) and patients with complications. ${ }^{1,7,8} \mathrm{An}$ association of Euthyroid sick syndrome in ACS with poorer prognosis has been suggested in few studies. ${ }^{1,6}$ It has further been stated that the euthyroid sick syndrome has special significance in patients of ACS because low T3 levels in these patients signify severe disease and can be used as a marker for early invasive management in these patients. ${ }^{6}$
Till date to my knowledge there are no data regarding thyroid profile in ACS patients from this part of world. This study aims to study the thyroid hormone profile in patients of ACS and to compare it in between STEMI and UA/NSTEMI groups.

\section{Methods:}

This is a hospital based, cross-sectional, comparative, observational study done from July 2015 to June 2017 in the department of cardiology of Manipal Teaching hospital, Nepal. 200 consecutive cases of acute coronary syndromes were taken for the study. Depending on the ECG findings and result of cardiac markers, the patients of ACS were categorized into following two groups as per American Heart Association (AHA) criteria. Group 1 considered cases showing ST depression / $\mathrm{T}$ wave inversion with normal or elevated cardiac markers. At the time of presentation, patients with UA and NSTEMI can be indistinguishable and therefore are considered together in these guidelines. ${ }^{9} \mathrm{UA}$ is defined as angina pectoris or equivalent ischemic discomfort with at least one of three features: (1) it occurs at rest (or with minimal exertion), usually lasting $>10$ minutes; (2) it is severe and of new onset (i.e., within the prior 4-6 weeks); and/or (3) it occurs with a crescendo pattern (i.e., distinctly more severe, prolonged, or frequent than previously). The diagnosis of NSTEMI is established if a patient with the clinical features of UA develops evidence of myocardial necrosis, as reflected in elevated cardiac biomarkers ${ }^{10}$ and Group 2

@Nepalese Heart Journal. Nepalese Heart Journal retains copyright and work is simultaneously licensed under Creative Commons Attribution License CC - BY 4.0 that allows others to share the work with an acknowledgement of the work's authorship and initial publication in this journal. 
included STEMI patients having symptoms of myocardial ischemia in association with electrocardiographic (ECG) ST elevation and release of biomarkers of myocardial necrosis. New $\mathrm{ST}$ elevation at the $\mathrm{J}$ point in at least 2 contiguous leads of 2 $\mathrm{mm}(0.2 \mathrm{mV})$ in men or $1.5 \mathrm{~mm}(0.15 \mathrm{mV})$ in women in leads $\mathrm{V} 2-\mathrm{V} 3 \mathrm{and} /$ or of $1 \mathrm{~mm}(0.1 \mathrm{mV})$ in other contiguous chest leads or the limb leads. ${ }^{11}$ The 12- lead ECG is a pivotal diagnostic tool. Level of serum cardiac biomarkers CKMB and Troponin are elevated. ${ }^{12}$ Known patients of thyroid disorders on treatment, patients suffering from other diseases such as neoplasia, chronic renal failure, chronic obstructive lung diseases, cirrhosis of liver and active infective conditions and patients taking Amiodarone, Lithium, Steroids or those who received iodinated contrast agent within the previous 2 weeks were excluded. Data were collected in a preformed proforma and analyzed in SPSS software version 16. The significant difference between two groups was compared using ANOVA. Pearson's correlation coefficient, Chi-square test, $\mathrm{t}$-tests, etc was used to find group association. Odds ratio was calculated for required appropriate values and $p$ values were considered significant at a predetermined level of $<0.05$.

\section{Results:}

Two hundred ACS patients between 23 years to 88 years with mean age of $61.33 \pm 12.30$ years were studied. $115(57.5 \%)$ were more than 60 years, $70(35 \%)$ were $40-60$ years and $15(7.5 \%)$ belonged to age group of $20-40$ years. $127(63.5 \%)$ were males. $116(58 \%)$ were STEMI patients while $84(42 \%)$ were UA NSTEMI patients. $76(39 \%)$ patients were hypertensive and on medications while only $21(10.5 \%)$ were diabetics. $134(67 \%)$ patients were smokers.

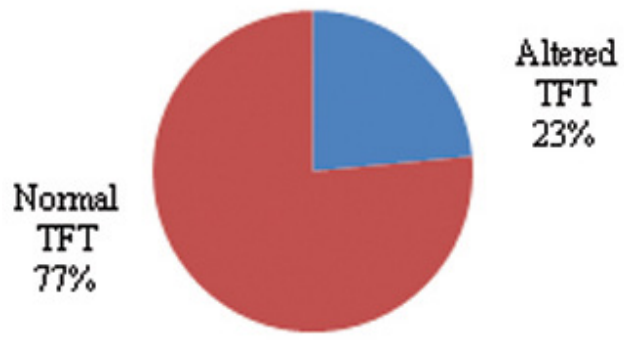

Figure 1: Thyroid hormone in pts with ACS

Thyroid hormone analysis was done in all the ACS patients and was found abnormal in $47(23.5 \%)$ of the patients. Out of 127 males and 73 females with ACS, 27 (21.25\%) patients had abnormal TFTs while 20 (27.39\%) female patients with ACS had abnormal TFTs. There was no statistically significant difference in prevalence of abnormal thyroid hormone profile in males and females with ACS $(\mathrm{p}=0.35)$.

\begin{tabular}{|l|ccccc|}
\hline \multicolumn{6}{|c|}{ Table 1: Pattern of abnormal thyroid profile in patients with different categories. } \\
\hline Category & $\begin{array}{l}\text { No of } \\
\text { pts with } \\
\text { Euthroid } \\
\text { sick } \\
\text { syndrome }\end{array}$ & $\begin{array}{l}\text { No of pts with } \\
\text { subclinical } \\
\text { hypothyroidism }\end{array}$ & $\begin{array}{l}\text { No of pts with } \\
\text { subclinical } \\
\text { hyperthyroidism }\end{array}$ & $\begin{array}{l}\text { No of pts } \\
\text { with low fT4 } \\
\text { but normal } \\
\text { fT3 and } \\
\text { TSH }\end{array}$ & $\begin{array}{l}\text { Total } \\
\text { pts with } \\
\text { abnormal } \\
\text { TFTs }\end{array}$ \\
\hline STEMI & 20 & 8 & 3 & 2 & 35 \\
\hline NSTEMI & 8 & 4 & 2 & 0 & 12 \\
\hline
\end{tabular}

Of the 47 patients with abnormal thyroid hormone profile, 28(59.5\%) had Euthyroid Sick Syndrome, 12(25.5\%) had subclinical hypothyroidism, $5(10.6 \%)$ had subclinical hyperthyroidism and $2(4.25 \%)$ had low fT4 with normal fT3 and normal TSH. Table 1 further divides the findings in subcategories of STEMI and UA/NSTEMI.

\begin{tabular}{|c|c|c|c|c|}
\hline Catagory & $\begin{array}{l}\text { Number of pts } \\
\text { with normal TFT } \\
\text { reports }\end{array}$ & $\begin{array}{l}\text { Number of pts } \\
\text { with abnormal } \\
\text { TFT reports }\end{array}$ & Odds ratio & $\begin{array}{l}\text { P-value(Fisher exact } \\
\text { probability test) }\end{array}$ \\
\hline STEMI & 81 & 35 & 2.59 & 0.006 \\
\hline UA/NSTEMI & 72 & 12 & & \\
\hline
\end{tabular}

Table 2 shows the comparison of abnormal TFT reports in patients with STEMI and UA/NSTEMI patients. It shows a statistical significant difference in TFT profile in these two groups

\begin{tabular}{|c|c|c|c|c|}
\hline Catagory & TFT reports & $\begin{array}{l}\text { Number of patients } \\
\text { with heart failure }\end{array}$ & $\begin{array}{l}\text { Number of patients } \\
\text { without } \\
\text { heart failure }\end{array}$ & $\begin{array}{l}\text { P-value(Fisher exact } \\
\text { probability test) }\end{array}$ \\
\hline \multirow[t]{2}{*}{ STEMI } & Normal & 7 & 73 & 0.001 \\
\hline & Abnormal & 12 & 23 & \\
\hline \multirow[t]{2}{*}{ UA/NSTEMI } & Normal & 2 & 70 & 0.003 \\
\hline & Abnormal & 4 & 8 & \\
\hline
\end{tabular}

The above table (table 3 ) shows that there was significant difference in patients woth abnormal TFT reports presenting or habing heart failure both in STEMI or UA/STEMI groups

\begin{tabular}{|c|c|c|c|c|}
\hline Category & TFT reports & $\begin{array}{l}\text { Mean average hospital stay } \\
\text { (in days) }\end{array}$ & $\begin{array}{l}\text { Mean difference } \\
(95 \% \mathrm{CI})\end{array}$ & P-value \\
\hline \multirow[t]{2}{*}{ STEMI } & $\operatorname{Normal}(\mathrm{n}=80)$ & $6+0.7$ & $\begin{array}{l}-3.0(-3.56 \text { to } \\
2.45\end{array}$ & $<0.001$ \\
\hline & Abnormal $(\mathrm{n}=35)$ & $9+2.3$ & & \\
\hline \multirow[t]{2}{*}{ UA/NSTEMI } & $\operatorname{Normal}(\mathrm{n}=72)$ & $5+1.1$ & $\begin{array}{l}-2.0(-2.79 \text { to } \\
-1.22)\end{array}$ & $<0.001$ \\
\hline & Abnormal $(\mathrm{n}=12)$ & $7+2.01$ & & \\
\hline
\end{tabular}

Further analysis in mean average hospital stay and mortality with abnormal thyroid hormone profiles in these patients was analyzed. The mean hospital stay was significantly higher $(p=<0.001)$ in both the groups (Table 4). Mortality was slightly higher in patients having abnormal TFT reports but not significant in both the groups ( $\mathrm{p}=0.164$ and 0.1429 respectively) (table 5).

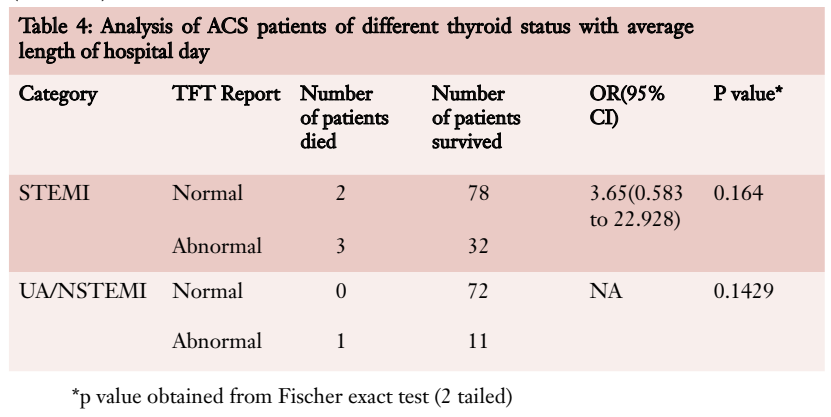




\section{Discussion:}

Alteration in the level of serum thyroid hormone profile has been described in various several non-thyroidal systemic illnesses including acute heart diseases in otherwise euthyriod patients which is called as "euthyroid sick syndrome". ${ }^{1-4}$ Present study assesses thyroid profile in ACS and compare between the ACS sub-groups. Our study showed abnormal thyroid hormonal findings in $47(23.5 \%)$ of patients with ACS. This result was comparable to various other studies in other part of the world too. For example a study of 400 patients of ACS by Qari FA, thyroid dysfunction was reported in $23.3 \%$ of patients. ${ }^{13}$ Similarly Khalil OA et al in their study of 196 patients of ACS, reported changes in thyroid hormone profile in $23 \%$ of their patients. ${ }^{14}$ Mathur $\mathrm{P}$ et al in their study of 85 patients and Bayrak A et al in their study of 110 patients of ACS reported changes in thyroid hormone profile in $31.7 \%$ and $23.6 \%$ of patients respectively. ${ }^{6,15}$

This study is done to see the status of thyroid profile in patients with ACS in our part of world. Our study showed a higher prevalence of abnormal thyroid hormone profile was seen in patients of STEMI group as compared to NSTEMI/UA group being 35 out of $47(74.46 \%)$ in STEMI group and 12 out of 47 $(25.56 \%)$ in NSTEMI/UA group. The difference is statistically significant $(\mathrm{p}=0.006)$. Similarly there was high prevalence of different thyroid patterns like euthyroid sick syndrome, subclinical hypothyroidism or hyperthyroidism and low fT4 but normal TSH and $\mathrm{fT} 3$ in STEMI group than UA/NSTEMI. These results are comparable to studies done before. ${ }^{6,13-15}$

Thyroid dysfunction in acute coronary syndrome increases the relative risk of death by 5.49 fold than euthyroid patients. ${ }^{13,14}$ Takada K et al in year 1994 in their study of relationship of thyroid function and left ventricular function in Acute Myocardial Infarction in 52 patients admitted to Coronary Care Unit within 24 hours after the onset observed that non-survivors showed significantly lower levels of fT3 and fT4 48 hours after onset, and concluded that measurement of thyroid hormone in AMI is important in evaluating the severity of the condition and waking a prognosis. ${ }^{16}$ Our study also showed higher rates of heart failure $(\mathrm{p}=0.001 \& 0.003$ in STEMI \& UA/NSTEMI respectively), longer length of hospital stay and high mortality in all types of ACS patients with abnormal thyroid profiles (refer table 3 and 4).

\section{Limitation:}

Cardiac enzymatic levels of troponins (quantitative) were not available in the laboratory of study area. Had it been there we could further compare the relationship with altered thyroid profile and level of troponins.

\section{Conclusion:}

There is higher prevalence of abnormal thyroid hormonal findings in ACS causing significant morbidity and mortality. As a future direction, thyroid hormone profile done at the time of admission in patients with ACS may be used as a marker of prognosis along with other established scores or biochemical markers.

References:

1. Pimentel RC, Cardoso GP, Escosteguy CC, Abreu LM.

Thyroid hormone profile in acute coronary syndromes. Arq Bras Cardiol .2006;(87): 629-34.

2. Hamilton MA, Stevenson LW, Luu M, Walden JA. Altered thyroid hormone metabolism in advanced heart failure. J Âm CollCardiol. 1990 Jul;16(1):91-95. https://doi. org/10.1016/0735-1097(90)90462-X

3. Eber B, Schumacher M, Langsteger W, Zweiker R, Fruhwald FM, Pokan R et al. Changes in thyroid hormone parameters after acute myocardial infarction. Cardiology. 1995;86(2):152-6. https://doi.org/10.1159/000176862

Cite this article as: Navaraj Paudel, Vijay Sha, Vijay Madhav et.al Thyroid profile as a marker of poor progonstic factor in patients with acute coronary syndrome: a tertiary care hospital based observational study. Nepalese Heart Journal 2018; 15(1) 39-41: http://dx.doi.org/10.3126/njh.v15i1.19715
4. Franklyn JA, Gammage MD, Ramsden DB, Sheppard MC. Thyroid status in patients after acute myocardial infarction. ClinSci (Lond). 1984 Dec;67(6):585-90. https://doi. $\mathrm{rg} / 10.1042 / \mathrm{cs} 0670585$

5. Clark RE. Cardiopulmonary bypass and thyroid hormone metabolism. Ann Thorac Surg. 1993 Jul;56(1 Suppl):S35-S42. https://doi.org/10.1016/0003-4975(93)90552-S

6. Abdulaziz Qari F. Thyroid Hormone Profile in Patients With Acute Coronary Syndrome, Iran Red Crescent Med J. 2015 ;17(7):e26919. https://doi.org/10.5812/ircmj.26919v2

7. Pavlou HN, Kliridis PA, Panagiotopoulos AA, Goritsas CP, Vassilakos PJ. Euthyroid Sick Syndrome in acute ischemic syndromes. Angiology. 2002 Nov-Dec;53(6):699-707. https:// doi.org/10.1177/000331970205300611

8. Friberg L, Drvota V, BjelakAH,Eggertsen G, Ahnve $\mathrm{S}$. Association between increased levels of reverse triiodothyronine and mortalitity after acute myocardial infarction. Am J.Med. 2001 Dec 15;111(9):699-703. https:// doi.org/10.1016/S0002-9343(01)00980-9

9. Anderson JL, Adams CD, Antman EM, Bridges CR, CaliffRM,Casey DE Jr, Chavey WE 2nd, Fesmire FM, Hochman JS, Levin TN, Lincoff AM, Peterson ED, Theroux P, Wenger NK, Wright RS. 2011 ACCF/AHAfocused update incorporated into the 2007 ACC/AHA guidelines for the management of patients with unstable angina/ non-ST-elevation myocardial infarction: a reportof the American College of Cardiology Foundation/American Heart Association Task Force on Practice Guidelines. Circulation. 2011;123:e426-e579. https://doi.org/10.1161/ CIR.0b013e318212bb8b

10. Canon CP, Braunwald E. Unstable angina and Non ST segment elevation Myocardial Infarction. In:Longo DL Kasper DL, Jameson JL, Fauci AS, Hauser SL, Loscalzo J, editors. Harrison's Principle of Internal Medicine.18th ed. New York: Mc Graw Hill; 2012.P 2015.

11. O'Gara PT, Kushner FG, Ascheim DD, Casey DE Jr, Chung MK, de Lemos JA, Ettinger SM, Fang JC, Fesmire FM, Franklin BA, Granger CB, Krumholz HM, Linderbaum JA, Morrow DA, Newby LK, OrnatoJP,Ou N, Radford MJ, Tamis-Holland JE, Tommaso CL, Tracy CM, Woo YJ, Zhao DX. 2013 ACCF/AHA guideline for the management of ST-elevation myocardial infarction: a report of the American College of Cardiology Foundation/American Heart Association Task Force on Practice Guidelines. J Am Coll Cardiol. 2013 Sep 10;62(11):1039. https://doi.org/10.1161/ CIR.0b013e3182742c84 https://doi.org/10.1016/j.jacc.2012.11.019

12. Antman EM, Loscalzo J. ST-Segment Elevation Myocardial Infarction. In:Longo DL, Kasper DL, Jameson JL, Fauci AS, Hauser SL, Loscalzo J, editors. Harrison's Principle of Internal Medicine.18th ed. New York: Mc Graw Hill; 2012. P 2021-2024. https://doi.org/10.1016/B978-1-4377-0398$6.00055-\mathrm{X}$ https://doi.org/10.1016/B978-1-4377-0398-6.00054-8

13. QariFA.Thyroid hormone profile in patients with acute coronary syndrome. Iran Red Crescent Med J. 2015 Jul;17(7):e26919.

14. Khalil OA, Abdelaziz A, Ghoniem ME, Elagrody AI, Elgendy SA, Fawzy MS. Thyroid dysfunction in acute coronary syndrome and its relation to morbidity and mortality. International Journal of Science and Research.2015 Jul;4(7):1564-1570.

15. Bayrak A, Bayr A, Karabulut KU. Effects of Thyroid hormones on major cardiovascular risk in acute coronary syndromes. Critical Care 2011,15(Suppl 1):P1 https://doi.org/10.1186/ cc9421

16. Takada K, Shimai S, Takano T, Hayakawa H. The prevalence and significance of abnormal thyroid hormone metabolism in acute myocardial infarction. Nihon IkaDaigakuZasski. 1994 Jun;61(13):220-31. https://doi.org/10.1272/jnms1923.61.220 